IZA DP No. 9645

Television, Cognitive Ability, and High School Completion

Øystein Hernæs

Simen Markussen

Knut Røed

January 2016

Forschungsinstitut zur Zukunft der Arbeit Institute for the Study of Labor 


\title{
Television, Cognitive Ability, and High School Completion
}

\author{
Øystein Hernæs \\ Ragnar Frisch Centre for Economic Research, University of Oslo \\ and European University Institute
}

Simen Markussen

Ragnar Frisch Centre for Economic Research

Knut Røed

Ragnar Frisch Centre for Economic Research

and IZA

\author{
Discussion Paper No. 9645 \\ January 2016
}

IZA

P.O. Box 7240

53072 Bonn

Germany

Phone: $+49-228-3894-0$

Fax: +49-228-3894-180

E-mail: iza@iza.org

Any opinions expressed here are those of the author(s) and not those of IZA. Research published in this series may include views on policy, but the institute itself takes no institutional policy positions. The IZA research network is committed to the IZA Guiding Principles of Research Integrity.

The Institute for the Study of Labor (IZA) in Bonn is a local and virtual international research center and a place of communication between science, politics and business. IZA is an independent nonprofit organization supported by Deutsche Post Foundation. The center is associated with the University of Bonn and offers a stimulating research environment through its international network, workshops and conferences, data service, project support, research visits and doctoral program. IZA engages in (i) original and internationally competitive research in all fields of labor economics, (ii) development of policy concepts, and (iii) dissemination of research results and concepts to the interested public.

IZA Discussion Papers often represent preliminary work and are circulated to encourage discussion. Citation of such a paper should account for its provisional character. A revised version may be available directly from the author. 


\section{ABSTRACT}

\section{Television, Cognitive Ability, and High School Completion*}

We exploit supply-driven heterogeneity in the expansion of cable television across Norwegian municipalities to identify developmental effects of commercial television exposure during childhood. We find that higher exposure to commercial television reduces cognitive ability and high school graduation rates for young men. The effects are largest for exposure during pre-school and elementary school age. We find no effect on high school completion for women, suggesting availability of non-educational media content as a factor in the widening educational gender gap. Based on time-use data, we show that a possible explanation is that television-watching crowds out reading more for boys than girls.

JEL Classification: J13, J16, J24, L82

Keywords: human capital, media, education gender gap

Corresponding author:

Øystein Hernæs

The Ragnar Frisch Centre for Economic Research

Gaustadalléen 21

0349 Oslo

Norway

E-mail: ohernaes@gmail.com

\footnotetext{
" This paper is part of the project "Social Insurance and Labor Market Inclusion in Norway", funded by the Norwegian Research Council (grant \#202513). Administrative registers made available by Statistics Norway have been essential. Data on ability scores have been obtained by consent from the Norwegian Armed Forces, who are not responsible for any of the findings and conclusions reported in the paper. We thank Peter Fredriksson, Tarjei Havnes, Andrea Ichino, and Andrea Mattozzi for valuable comments.
} 


\section{Introduction}

Since television was introduced to a large audience around the mid-20th century, its effects have been debated. A widespread concern has been that television encourages a particularly passive form of engagement, and thus may be damaging to intellectual development. This view has been argued by social commentators (e.g. Postman, 1985), but has also received support in professional circles: American pediatricians have concluded that television affects children negatively, and recommend limiting children's television time (American Academy of Pediatrics, 2001; Strasburger, Jordan, and Donnerstein, 2010). The complete opposite view has also found supporters. Johnson (2006), for example, argues that popular culture, including television, has become more complex and intellectually demanding over time and that this gives beneficial cognitive payoffs.

Cognitive skills are essential for individual (Griliches and Mason, 1972; Cunha and Heckman, 2007) as well as aggregate economic outcomes (Hanushek and Woessmann, 2008). After a long period with generally rising IQ scores in industrialized countries, recent empirical evidence indicates that this development may now have gone into reverse; see Dutton and Lynn (2015) for a recent overview of the literature. ${ }^{1}$ Since its introduction, television has spread all over the world; hence, its effects are also likely to be ubiquitous. If television viewing indeed can be harmful to the development of cognitive skills, this may be one explanation why IQ scores have stagnated or even started to decline in many countries. If so, this is critical knowledge for policy makers and families alike.

\footnotetext{
${ }^{1}$ Recent negative trends in IQ scores have been reported for Norway (Sundet, Burlaug, and Torjussen, 2004), Australia (Cotton et al., 2005), Denmark (Teasdale and Owen, 2008), Britain (Shayer, Ginsburg, and Coe, 2007), Sweden (Ronnlund et al., 2013), the Netherlands (Woodeley and Meisenberg, 2013), Finland (Dutton and Lynn, 2013), and France (Dutton and Lynn, 2015).
} 
The existing empirical evidence is not conclusive, however. In a review of the pediatrics literature, Jolin and Weller (2011) point out that statistical evaluations are often based on cross-sectional data, and they lament the lack of longitudinal research designs. There are some experimental studies focusing on short-term impacts, but the external validity of such studies is questionable; see Thakkar, Garrison Christiakis, (2006) for a review. An influential study within the economics literature is Gentzkow and Shapiro (2008), who analyze the effect of the introduction of television in the US in the 1940s and 1950s on standardized test scores. They find that, contrary to popular worries, television exposure during pre-school age not only failed to lower test scores, but in fact raised reading and general knowledge scores for socially disadvantaged groups. On the basis of this effect heterogeneity, they conclude that "the cognitive effects of television exposure depend critically on the educational value of the alternative activities that it crowds out (p. 282)." As most societies have undergone large changes in their educational and home environments since the early post-war era, this makes it pertinent to reexamine the issue. The impacts of television exposure also clearly depend on the contents of the programs that children are exposed to. Kearney and Levine (2015) examine the effects of the introduction of an explicitly educational children's show - Sesame Street - into a television programming space dominated by entertainment shows. They find support for the positive educational effect of Sesame Street, in particular for boys and children from disadvantaged backgrounds.

In this paper, we examine how a geographically staggered expansion of access to commercial cable television in Norway during the 1980s and 1990s affected children's cognitive skill developments and subsequent high school graduation rates. As we explain in more detail below, the introduction of cable television in Norway had huge impacts both on children's overall exposure to television and on the type of programs they watched. Whereas the state broadcaster, which held a legal monopoly on television broadcasts until 1981, offered 
a single TV channel only, based on a clear educational mandate, the new commercial channels were almost entirely dominated by light entertainment without any educational content. We provide empirical support for the view that the expansion of commercial cable television indeed had negative effects on men's cognitive skills - as measured by intelligence test scores at time of military service enrolment - and that it also reduced their high school completion rates. For women, we find no effects on high school completion rates. Data on intelligence test scores exist only for men.

When television was deregulated in Norway in the beginning of the 1980s, it became legal to forward television signals broadcast by satellites in local cable networks, and a large rollout of cable networks was initiated. We argue that the growth in cable networks was a supply-led development driven by geographical factors and settlement patterns, and the key explanatory variable in our analysis is the time-varying cable television coverage rate at the municipality level. Because residence decisions may be endogenous to cable television coverage, we use the future coverage in an individual's municipality of birth to instrument for his or her actual exposure. To account for unobservable factors possibly related to both television adoption and outcomes, we include in our regressions a wide range of region-by-year and other controls, including also municipality fixed effects and time-varying socio-economic variables at the municipality level. Further, due to the richness of our data, we are able to control for relevant parental characteristics in order to improve precision and account for possible selection.

Our results indicate that one year of living in a municipality with full coverage of cable television during childhood and adolescence lowers ability test scores of young men by $0.53 \%$ standard deviations, corresponding to 0.08 IQ points. It reduces the high-school completion rate for males by 0.33 percentage points. These effects seem to be driven by consumption of light television entertainment crowding out more cognitively stimulating activities such as reading. The negative impacts of commercial television access are largest during elementary 
school age. For women, we do not find convincing evidence of a negative effect on high school completion, thus a net effect was to widen the educational gender gap. A policy lesson regarding all forms of media that provide content with low educational value is that although consumption of such content is not necessarily harmful in itself, one should be alert about what activities it substitutes for, in particular for boys.

Our paper adds to a rapidly growing literature in economics on the effects of media. Television in particular has been found to impact outcomes as diverse as voter turnout in the US (Gentzkow, 2006), party choice in the US and Russia (DellaVigna and Kaplan, 2007; Enikolopov, Petrova, and Zhuravskaya, 2011; Martin and Yurukoglu, 2014), social capital in Indonesia (Olken, 2009), fertility, women's status and school enrollment in India (Jensen and Oster, 2009), and divorce and fertility in Brazil (Chong and Ferrara, 2009; La Ferrara, Chong, and Duryea, 2012).

Our study also adds to the literature on the educational gender gap. In most developed nations, girls have higher high school graduation rates than boys (OECD, 2014). In the US, girls had in fact higher high school graduation rates than boys for the most part of the twentieth century (Goldin and Katz, 2008); however from the 1970 the gap has widened (Murnane, 2013). In the same period, girls also made gains relative to boys on standardized math and reading tests (Goldin, Katz, and Kuziemko, 2006; Cho, 2007) and grades (Fortin, Oreopoulos, and Phipps, 2015). Previous research has found evidence that boys are more sensitive than girls with respect to both parental (Bertrand and Pan, 2013; Riphahn and Schwientek, 2015) and school/preschool inputs (Krueger, 1999; Machin and McNally, 2008; Chetty et al., 2011; Havnes and Mogstad, 2011). This is supported by evidence showing that boys benefit more strongly than girls from early childhood interventions (Campbell et al., 2014; Conti, Heckman, and Pinto, 2015) and are more impatient (Bettinger and Slonim, 2007; 
Dohmen, Falk, and Sunde, 2010; Castillo, Ferraro, Jordan, and Petrie, 2011; Golsteyn, Grönqvist, and Lindahl, 2014).

\section{Data and institutional background}

Television was introduced in Norway in the 1960s. Until 1981, the state-controlled Norwegian Broadcasting Corporation held a legal monopoly on broadcasting in the country, and for most Norwegians, only a single TV-channel was available. In December 1981, the newly elected government announced that 30 other agents would obtain broadcasting licenses the following year, thereby breaking the public monopoly. It then became legal to forward television signals broadcast by satellites in local cable networks. All such local cable networks had to register with the Post- and Telecommunications Authority. The legalization in 1981 initiated a large-scale roll-out of local cable networks. Because of economies of scale in laying the necessary cables, the roll-out took place primarily in densely populated areas (Norwegian Ministry of Culture, 1995). Mandatory registration continued until 2004, at which point $40 \%$ of the population was covered. The aggregate evolution of the number of households covered is shown in Figure I.

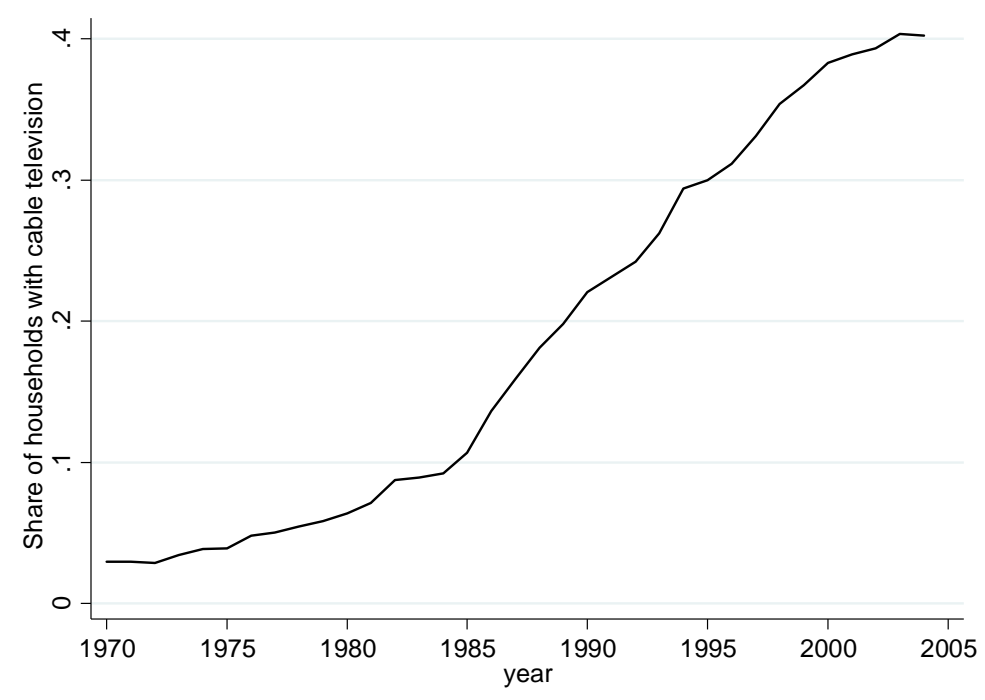

Figure I. Share of households with cable television 1970-2005 
The television data consist of the universe of Norwegian local cable networks up to 2004 . They contain more than 11,000 unique networks, each with the number of households covered, the first date of operation, and the municipality. We combine this with data on the number of households in a municipality to obtain the yearly coverage rate in each municipality up to 2005. The maps in Figure II show three snapshots of coverage rates across the country between 1985 and 2005. They illustrate the considerable geographical disparities in the roll-out process, with cable networks first established in the Oslo-area, and then expanded to other densely populated areas throughout the country. To arrive at individualized exposed-to-TV-variables, we construct two variables for each person born between 1974 and 1987: the cumulative cable TV coverage over their first 18 years both in their municipality of actual residence at any time and in their municipality of birth. The resultant TV coverage variables thus vary from zero (for individuals who never had access to cable TV before age 18) to 18 (for individuals who had access throughout their childhood and adolescence). 


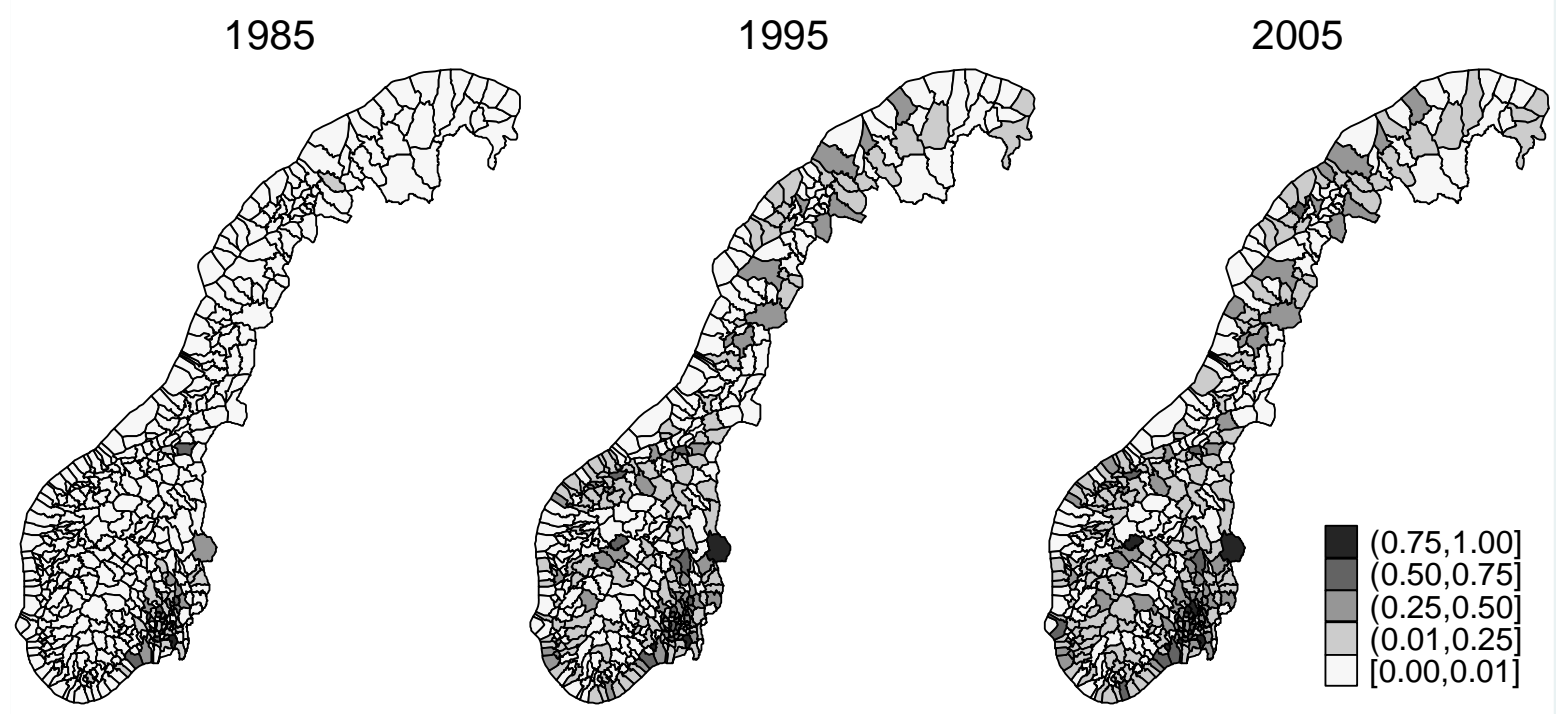

Figure II. Cable television coverage by municipality, 1985-2005

Unfortunately, we do not have the same kind of data on commercial television coverage by parabolic antennas. This is a minor problem in the present context, however, as parabolic antennas were providing only a small amount of television coverage in this period. When Statistics Norway started their media survey in 1991, only $5 \%$ of the households had a parabolic antenna. Since parabolic antennas and cable television were substitutes for each other, the presence of parabolic antennas will nevertheless tend to attenuate our estimated effects of commercial television access slightly, as we implicitly will assume that cable networks are the only providers of these channels.

Coinciding with the expansion of commercial television in Norway, there has been a marked change in the way young people spend their leisure time. Figure III illustrates some key findings from a sequence of time use surveys provided by Statistics Norway. 
Unsurprisingly, time spent watching television increased considerably for both boys and girls during the 1980s and 1990s. To a large extent, this substituted for reading, particularly among boys, for which time spent reading dropped by as much as 74 percent; from 39 minutes per day in 1980 to 10 minutes per day in 2000 .

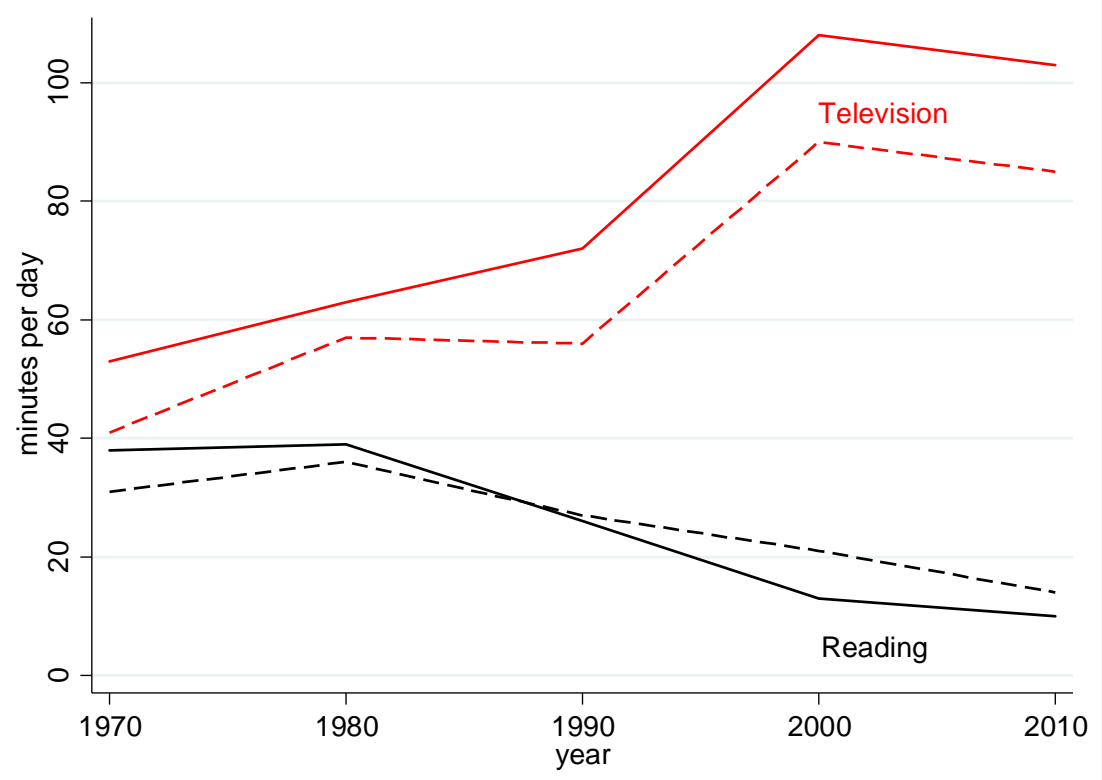

Figure III. Minutes Spent An Average Day On Television Wathcing and Reading, Boys (Solid Lines) and Girls (Dotted Lines) Aged 16-24.

Source: Statistics Norway; time use surveys collected in 1970, 1980, 1990, 2000, and 2010.

The data we use in the statistical analysis stem from different administrative registers, and cover the complete population. The outcomes we focus on are cognitive ability score at age 18 for young men, and a dichotomous variable indicating high-school completion by age 21 (two years after the "normal" graduation age) for both men and women. Our measure of cognitive ability is based on data from the Norwegian Armed Forces. Before compulsory military service, all Norwegian men undergo an assessment of suitability. From 1969/70, this assessment has included intelligence testing. All test-takers receive a score which is a composite of three tests, on arithmetic, word similarities and figures. In this paper we have standardized the test scores, thus point estimates will be directly interpretable as percentage 
points of a standard deviation, though for expositional purposes we sometimes refer to the corresponding IQ scores.

Figure IV (left panel) shows that there has indeed been a negative development on this test since the early 1990s, in line with previous findings reported by Sundet, Burlaug, and Torjussen (2004). Another notable phenomenon was a widening of the gender gap in high school completion, which increased by more than 6 percentage points (right panel).
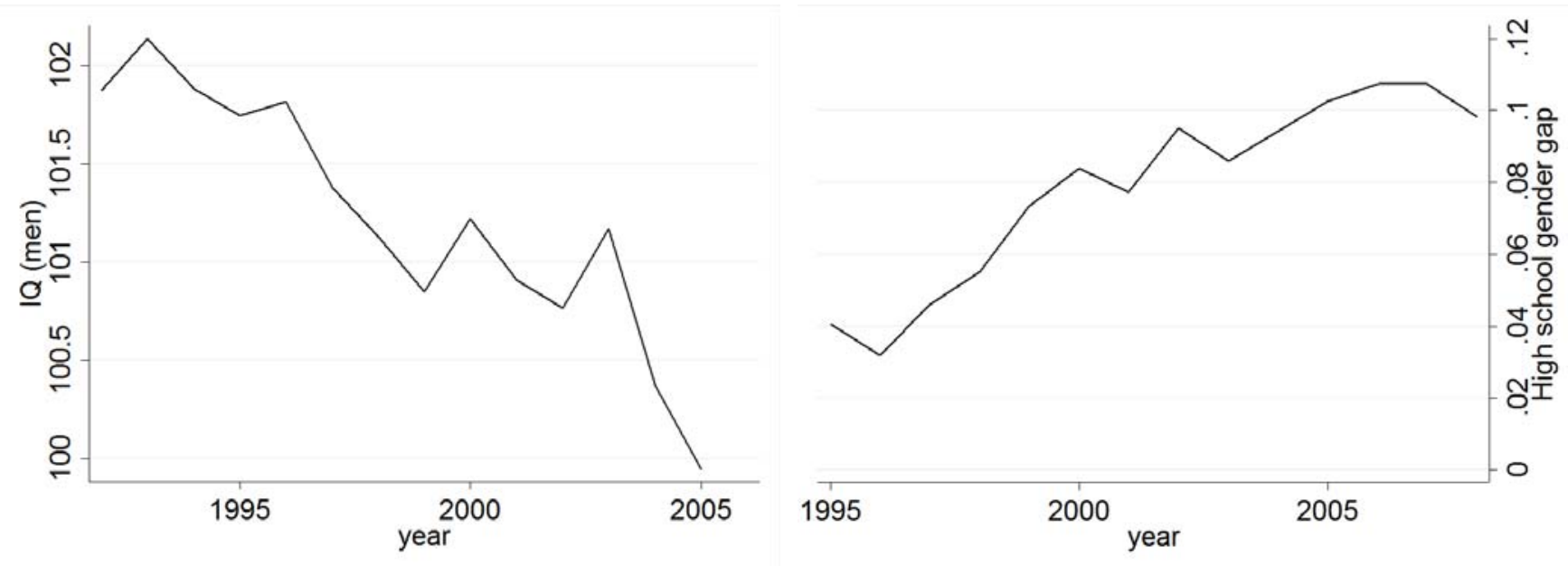

Figure IV

Left: IQ of Norwegian Conscripts 1992-2005.

Right: Female-male gender gap in high school completion at 21.

Note: The IQ test was normed on the test cohort of 1980, which provides the reference point (i.e. 1980 mean $=100$ ).

We match the two outcomes with data on parental characteristics and on the municipality of residence from the year of birth and onwards. The first cohort in our sample is the cohort born in 1974, which is the first year from which we have data on residence at birth. We include all subsequent cohorts until and including the one born in 1987, which turned 18 years old in 2005 . The reason why we stop at the 1987 birth cohort is that we do not have the data needed to compute total cable television coverage for later cohorts, as the mandatory registration of networks ended in 2004. To sum up, our sample consists of the birth cohorts 
1974-1987, with outcomes measured in 1992-2005 (ability test scores) and 1995-2008 (high school completion). To allay worries concerning an increasing share of people with immigrant background taking the test, we include only individuals born in Norway to Norwegian-born parents.

Table I presents an overview of the data we use in this paper, with descriptive statistics for the two outcomes and for the various control variables we are going to use in the statistical analysis. In total, we have around 311,000 observations. On average, the persons in our dataset had access to cable TV in only 3.45 years during their childhood and youth. But TV exposure increased considerably over time, from less than 2 exposure-years for our first cohorts to more than 5 for our last (not shown in the table). The control variables are defined at the individual or at the municipality-by-cohort levels, in both cases measured no later than the time of birth. In addition, we will in some cases use municipality characteristics measured in 1980 (pre-legalization) interacted with time-indicators. Individual characteristics comprise the educational attainment and earnings levels of both parents, whereas municipality characteristics cover socio-economic factors, such as average education, employment, and earnings; see Table I for details. 
Table I. Descriptive Statistics

\begin{tabular}{|c|c|c|c|c|c|c|}
\hline & \multicolumn{2}{|c|}{ Boys } & \multicolumn{2}{|c|}{ Girls } & \multirow{2}{*}{$\frac{\min }{\min }$} & \multirow{2}{*}{$\frac{\max }{\max }$} \\
\hline & mean & $\mathrm{sd}$ & mean & $\mathrm{sd}$ & & \\
\hline \multicolumn{7}{|l|}{ Outcomes } \\
\hline $\begin{array}{l}\text { ability test score at age } 18 \\
\text { (standardized) }\end{array}$ & 0.08 & $(0.87)$ & & & -2.00 & 2.00 \\
\hline high school completed at age 21 & 0.67 & $(0.47)$ & 0.75 & $(0.47)$ & 0.00 & 1.00 \\
\hline \multicolumn{7}{|l|}{ Main explanatory variable } \\
\hline $\begin{array}{l}\text { TV, actual years of coverage until } \\
\text { age } 18 \text { (municipality of residence) }\end{array}$ & 3.31 & $(3.54)$ & 3.29 & $(3.52)$ & 0.00 & 18.00 \\
\hline $\begin{array}{l}\mathrm{TV} \text {, potential years of coverage until } \\
\text { age } 18 \text { (birth municipality) }\end{array}$ & 3.45 & $(3.70)$ & 3.42 & $(3.69)$ & 0.00 & 18.00 \\
\hline \multicolumn{7}{|l|}{ Controls } \\
\hline \multicolumn{7}{|l|}{$\begin{array}{l}\text { Parental characteristics in birth } \\
\text { year }\end{array}$} \\
\hline education father, four levels & 1.98 & $(0.83)$ & 1.98 & $(0.82)$ & 1.00 & 4.00 \\
\hline education mother, four levels & 1.83 & $(0.73)$ & 1.83 & $(0.73)$ & 1.00 & 4.00 \\
\hline income father, 1000 USD & 69.11 & $(30.44)$ & 69.09 & $(30.47)$ & 0.00 & 259.09 \\
\hline income mother, 1000 USD & 20.94 & $(22.87)$ & 20.76 & $(22.83)$ & 0.00 & 259.09 \\
\hline \multicolumn{7}{|l|}{$\begin{array}{l}\text { Municipality characteristics in } \\
\text { birth year }\end{array}$} \\
\hline schoolyears attained & 11.45 & $(0.44)$ & 11.44 & $(0.44)$ & 8.90 & 12.84 \\
\hline income males, 1000 USD & 62.57 & $(8.17)$ & 62.54 & $(8.15)$ & 31.39 & 88.98 \\
\hline income females, 1000 USD & 25.52 & $(7.30)$ & 24.46 & $(7.28)$ & 6.58 & 45.94 \\
\hline employment rate males & 0.80 & $(0.04)$ & 0.80 & $(0.04)$ & 0.42 & 0.90 \\
\hline employment rate females & 0.44 & $(0.12)$ & 0.44 & $(0.12)$ & 0.08 & 0.71 \\
\hline \multicolumn{7}{|l|}{$\begin{array}{l}\text { Municipality characteristics pre } \\
\text { reform (1980) }\end{array}$} \\
\hline schoolyears attained 1980 & 11.45 & $(0.41)$ & 11.45 & $(0.41)$ & 10.14 & 12.63 \\
\hline income males 1980, 1000 USD & 64.43 & $(7.28)$ & 64.40 & $(7.26)$ & 38.75 & 82.53 \\
\hline income females 1980,1000 USD & 25.88 & $(5.51)$ & 25.85 & $(5.50)$ & 12.72 & 37.48 \\
\hline employment rate males 1980 & 0.81 & $(0.03)$ & 0.81 & $(0.03)$ & 0.56 & 0.89 \\
\hline employment rate females 1980 & 0.45 & $(0.09)$ & 0.45 & $(0.09)$ & 0.18 & 0.62 \\
\hline population density 1980 & 0.69 & $(0.27)$ & 0.69 & $(0.27)$ & 0.00 & 0.99 \\
\hline average ability level 1980 & -0.03 & $(0.19)$ & 4.93 & $(0.18)$ & -0.68 & 0.43 \\
\hline Observations & 310430 & & 293643 & & & \\
\hline
\end{tabular}

Note: Parental education in four levels (less than high school, completed high school, university bachelor, university master); income is yearly earnings measured in 2013 prices, converted to USD with an exchange rate of $1 \mathrm{USD}=6.5 \mathrm{NOK}$ and right-censored at 20 times the "basic amount" used by the Norwegian Social Insurance Scheme; all municipality level covariates are based on inhabitants with Norwegian-born parents; municipality level income and employment are calculated based on inhabitants aged 18-60; in calculating employment rates, we count as employed individuals with yearly earnings at least 2 times the basic amount, corresponding to around USD 26000 ; population density is defined as the share of the municipality inhabitants living in a "densely populated" area. 


\section{Empirical strategy}

In order to identify the causal impacts of cable network expansion on the ability test score and schooling outcomes, we use the municipality-by-cohort specific coverage rate described in Section 2 as the key explanatory variable. The identifying assumption is then that the geographical rollout of cable TV was as good as randomly assigned with respect to other factors that could have generated local variations in the developments of cognitive ability and high school completion rates, conditional on the control variables we use in the analysis. We argue that we can rule out reverse causation in this case, as there is evidence that the cable network expansion during the 1980s and 1990s was solely supply side driven. Building cable networks required heavy investment in infrastructure, and was only profitable in densely populated areas. Given that there was a large excess demand for cable TV everywhere, the actual expansion pattern was determined by economies of scale and physical/topological constraints. Participants from the supply side of the cable television market in this period have confirmed that it is hard to see any factors other than suppliers' capacity and population density that had an impact on where networks were built, and that the deregulation suddenly allowed suppliers to cater to a demand that had been present for a long time. ${ }^{2}$ Further evidence for the exogeneity of coverage comes from considering the size and distribution of the networks. Many networks in a locality were constructed at the same time as parts of the same development. The average number of new households gaining access conditional on expansion in any given municipality-year, which is our observational unit, is 691. Thus it is clear that access was determined at a quite different level than the household. The fact that cable networks did not operate in almost $40 \%$ of municipalities (163 of 430) also shows that whether to obtain access was clearly not an individual-level decision.

\footnotetext{
2 Former head of the union of commercial cable-TV operators in Norway, Knut Børmer; personal communication. Terje Frøsland, of the state owned Norwegian Telecommunications (Televerket, from 2005 Telenor); personal communication.
} 
In 1999, a government White paper concluded that "significant development of cable networks beyond today's level will most likely not be profitable (Norwegian Ministry of Culture, 1999, Ch. 2.2)," and that "one does not expect significant further development of cable utilities beyond today's coverage of around $38 \%$ (Norwegian Ministry of Culture, 1999, Ch. 2.3)." From Figure 1 we see that this assessment proved correct. The report cites topographical and physical barriers as reasons for why full coverage would not be possible.

As an empirical check on the supply-driven expansion pattern, we run a regression where we use the potential years of coverage (in the municipality of birth) as the dependent variable and a number of pre-expansion (1980) municipality characteristics as explanatory variables. As can be seen from the results reported in Table II, the only variable that is related to subsequent cable television expansion in a statistically significant way is population density. 
Table II

TV Exposure in Birth Municipality as Dependent Variable. Regression Results.

\begin{tabular}{lc}
\hline \hline & $\begin{array}{c}(1) \\
\text { Cable TV } \\
\text { coverage, years }\end{array}$ \\
\hline \hline Baseline municipality characteristics & \\
Average schoolyears 1980 & 1.61 \\
Average income males 1980 & $(1.10)$ \\
$\quad$ 1000 USD & 0.09 \\
Average income females 1980, & $(0.07)$ \\
$\quad$ 1000 USD & -0.23 \\
Employment rate males 1980 & $(0.35)$ \\
& -9.54 \\
Employment rate females 1980 & $(8.62)$ \\
& 16.35 \\
Average male ability 1980 & $(19.05)$ \\
& 0.57 \\
Population density 1980 & $(1.07)$ \\
& 3.38 \\
cohort f.e. & $(1.36)$ \\
ymean & $* *$ \\
N obs & Yes \\
N municipalities & 3.44 \\
\hline \hline Note: Relation between cable television & 604073 \\
municipality covariates in 1980. Standard errors clustered & 430 \\
on municipality. Standard errors in parentheses. $*$ p $<0.10$, \\
$* *$ p $<0.05, * *$ p $<0.01$. & \\
\hline
\end{tabular}

Although demand did not play a significant role for the rollout of cable TV in Norway, we cannot a priori rule out that the (typically densely populated) areas selected for early expansion have been characterized by different developments in ability scores and schooling outcomes than other areas for reasons unrelated to the cable television expansion. Hence, as we detail below, an important element of our empirical strategy is to control for other possible geographically differentiated trends.

To empirically assess the impacts of cable TV coverage, we use linear regression models with the two outcomes (cognitive ability score and a dichotomous indicator for high school completion) as dependent variables and the number of years with cable TV coverage until age 
18 as the central explanatory variable. Although we have argued that individuals were unable to influence the geographical pattern of cable television expansion, they could obviously ensure own access by migrating to a place with coverage. Hence, the actual municipality of residence is potentially endogenous. We will apply instrumental variables models to deal with this problem; i.e., we use the cumulative television coverage in an individual's municipality of birth over the same 18 years to instrument for actual coverage.

It may be argued that the ability test score is an ill-defined dependent variable in a linear regression framework, as the test score scale in principle is ordinal. However, in practice, we have seen that the ability scores fit well into a cardinal interval scale in relation to important outcomes such as annual earnings. This is illustrated in Figure V, where we have plotted average (standardized) male labor earnings at age 40 against ability score (based on 2013 earnings data). The relationship between earnings and ability score is close to linear. Based on this relationship, we have also attempted to rescale the ability score used in Equation (1) such that it actually measures the predicted earnings level at age 40, and thus anchored the test score in an outcome of substantive economic interest. This made essentially no difference for the results, however; hence in the remaining of this paper, we focus on the results where we have used the ability test score directly as the left hand side variable.

Let $i$ be a subscript for individuals, $m$ for municipality of birth, $c$ for county of birth, and $t$ for year of birth. We can then write our baseline second step regression model (to be further explained below) as:

$$
y_{i}=\beta \widehat{T V}_{a}+\delta_{m}+\Theta_{c t}+s_{m t} \zeta+p_{i} \eta+\left(m_{0} \times I_{t}\right) \lambda+\varepsilon_{i m t}
$$

where $y_{i}$ is an individual outcome measured at age 18 or age $21, \widehat{T V}_{a}$ is predicted cumulative cable TV exposure during the first 18 living years, $\delta_{m}$ is a birth-municipality fixed effect, $\Theta_{c t}$ is a birth-county-birth-year fixed effects, $\left(s_{m t}, p_{t}\right)$ are vectors of socioeconomic municipality characteristics at the year of birth and parental characteristics, 
respectively, and $\left(m_{0} \times I_{t}\right)$ is a vector of pre-reform (1980) birth-municipality characteristics $\left(m_{0}\right)$ interacted with birth-year dummy variables $\left(I_{t}\right)$. The predicted cable TV exposure is the linear prediction from a first stage equation where actual TV exposure (based on correctly assigned municipality in every year) is the left-hand side variable and the corresponding TV exposure in the municipality of birth is the right-hand side variable, together with the municipality and county specific controls included in (1).

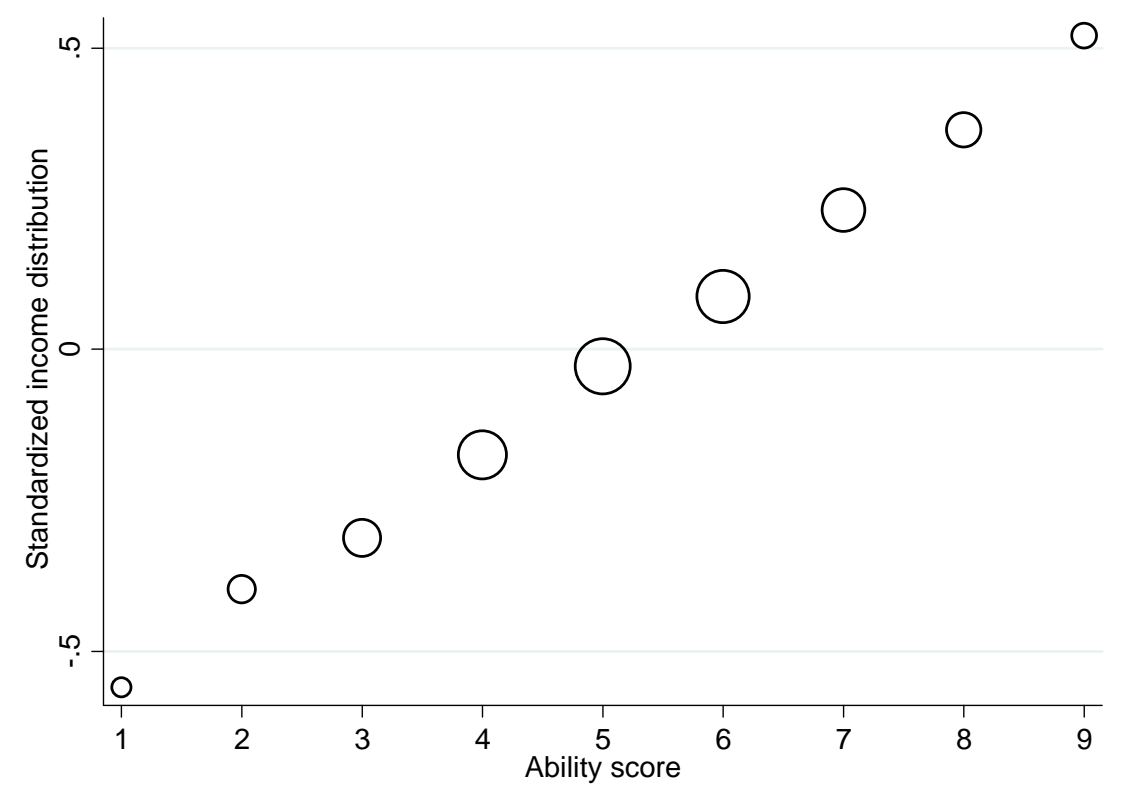

Figure $\mathrm{V}$

Standardized income at age 40 by ability test score

Note: Data based on income of 40-year old men in 2013. Income is first averaged by ability score, then standardized.

An important point to note is that all the explanatory variables in (1) are predetermined at birth or earlier. The birth-municipality fixed effects are included to control for any time-invariant factors that vary between municipalities in a way that correlates with cable TV expansion. We can obviously not use municipality-year fixed effects, as that would totally absorb also the effects of interest. However, by including regional birth-year fixed effects at a somewhat higher geographical level, we can control for time variations that are common within regions. There are 19 counties in Norway, and each county covers approximately 23 
municipalities on average. A somewhat unfortunate consequence of using county-year fixed effects is that we effectively throw out observations from Oslo, the capital city, which is by far the largest municipality and forms its own county. However, we exploit these data in a separate analysis, where we use observations from the largest cities/municipalities only (without county-year dummy variables).

The vector of time-varying socioeconomic municipality characteristics $s_{m t}$ is included to account for local trends in observed cohort composition that potentially vary across municipalities. The vector includes municipality-level average education, male and female income, and male and female employment rates; see Table I for details. These are all measured in the year of each cohort's birth; hence, they are not absorbed by the municipality-fixed effects (which are common for all cohorts). The vector of parental characteristics $p_{i t}$ includes parental income and indicator variables corresponding to four different categories of completed education. As with the municipality covariates, the parental characteristics are measured in the year of birth of the individual. The interactions of the pre-reform (1980) municipal characteristics and a vector of birth-year dummy variables are included in the manner of Duflo (2001) to control for unobserved local trends in outcomes that vary systematically with factors which potentially influenced network expansion. Since population density was a particularly important factor behind the cable network expansion, we include the 1980 level of population density among the municipal characteristics in this exercise. ${ }^{3}$ We also interact the municipalities' pre-reform (1980) average ability level among men with year of birth dummies in the same way in order to account for possible influences of mean-reversion tendencies in the data.

\footnotetext{
${ }^{3}$ We have also estimated the model using a categorization of population density in deciles in this interaction in stead of using it directly as a scalar. This makes essentially no difference for the results.
} 


\section{Main results}

The first stage and reduced form estimation results are reported in Table III. The first stage results show that there is a very high correlation between cable television coverage in the municipalities of actual residence and in the municipality of birth. The instrument is powerful. The three final columns show the reduced form effects, using our main model from equation (1) and cable television exposure in individuals' municipality of birth only. The results are a clear preview of what we are going to find later - negative effects for both cognitive ability and high school completion for men and zero effects for women.

Table IV presents our main estimation results in the form the second stage estimates for three alternative models, distinguished by different degrees of control for unobserved time trends interacted with pre-reform municipality characteristics. Note that all the models reported in Table IV contain municipality fixed effects as well as county-by-year fixed effects, in addition to parental characteristics and average municipality characteristics for each cohort. We consider these controls to be essential in order to isolate the presumed random-assignment-like variation in TV exposure, and thus disentangle the causal effects of interest from other potential sources of spatial variation in outcome developments. In the first row, we control for differential time developments correlated with pre-reform population density only, as this is the only variable we know for certain had a considerable impact the cable TV expansion pattern and, hence, represents the most likely source of omitted variable bias. In the second row, we add in the other pre-reform municipality characteristics, such as average education, income, and employment rates (see Table I). And in the final row we also add in the average pre-reform ability level among men. In all cases the pre-reform characteristics are interacted with birth-year dummy variables; hence there are no smooth-trend-assumptions involved in this exercise. Although each of the added variable 
groups contributes significantly to explaining the outcomes, the estimated effects of cable TV exposure remain stable.

Table III

First Stage and Reduced Form Results

\begin{tabular}{|c|c|c|c|c|c|}
\hline & \multicolumn{2}{|c|}{ First stage } & \multicolumn{3}{|c|}{ Reduced form } \\
\hline & Men & Women & & & Women \\
\hline & \multirow{2}{*}{\multicolumn{2}{|c|}{$\begin{array}{c}\text { Actual exposure, } \\
\text { years }\end{array}$}} & Standardize & High School & High School \\
\hline & & & Ability & Graduate & Graduate \\
\hline \multirow[t]{3}{*}{ Potential exposure, years } & 0.82 & 0.82 & -0.0044 & -0.0026 & -0.0002 \\
\hline & $(0.014)$ & $(0.014)$ & $(0.0024)$ & $(0.0012)$ & $(0.0012)$ \\
\hline & $* * *$ & $* * *$ & $*$ & $* *$ & \\
\hline Aggregate fixed effects & Yes & Yes & Yes & Yes & Yes \\
\hline Municipality covariates & Yes & Yes & Yes & Yes & Yes \\
\hline $\begin{array}{c}\text { Pre-reform characteristics } \\
\text { \# cohort fixed effects }\end{array}$ & Yes & Yes & Yes & Yes & Yes \\
\hline Parental covariates & No & No & Yes & Yes & Yes \\
\hline$\overline{F(\text { instrument) }}$ & 3435 & 3444 & 3 & 5 & 0 \\
\hline $\mathrm{N}$ obs & 310427 & 293641 & 279954 & 310427 & 293641 \\
\hline $\mathrm{N}$ muncipalities & 430 & 430 & 430 & 430 & 430 \\
\hline
\end{tabular}

Note: "Aggregate fixed effects" includes municipality fixed effects and county-year fixed effects. "Municipality covariates" includes average years of schooling attained, male and female income levels, male and female employment rates, all measured in the year of birth. "Pre-reform characteristics" includes 1980 levels of the share of the municipality inhabitants living in a "densely populated" area, the municipality covariates, and average ability score of men residing in the municipality. "Parental covariates" includes education level fixed effects and income for both parents, all measured in the year of birth. Standard errors clustered on municipality. Standard errors in parentheses. ${ }^{*} \mathrm{p}<0.10,{ }^{* *} \mathrm{p}<0.05, * * * \mathrm{p}<0.01$. 
Table IV

Main results. Instrumental Variables Estimates of the Effects of One Additional Year With Cable Television Coverage

\begin{tabular}{|c|c|c|c|c|}
\hline & & \multicolumn{2}{|c|}{ Men } & \multirow{2}{*}{$\begin{array}{c}\text { Women } \\
\text { High School } \\
\text { graduate }\end{array}$} \\
\hline & & $\begin{array}{l}\text { Standardized } \\
\text { Ability } \\
\end{array}$ & $\begin{array}{l}\text { High School } \\
\text { graduate }\end{array}$ & \\
\hline & Aggregate fixed effects & -0.0068 & -0.0036 & -0.0005 \\
\hline & + municipality and parental covariates & $(0.0029)$ & $(0.0015)$ & $(0.0017)$ \\
\hline & $\begin{array}{l}\text { + Pre-reform population density } \\
\text { \# cohort fixed effects }\end{array}$ & $* *$ & $* *$ & \\
\hline \multirow[t]{3}{*}{ (2) } & + Pre-reform municipality covariates & -0.0054 & -0.0031 & -0.0001 \\
\hline & \#cohort fixed effects & $(0.0029)$ & $(0.0015)$ & $(0.0015)$ \\
\hline & & $*$ & $* *$ & \\
\hline & + Pre-reform ability & -0.0053 & -0.0033 & -0.0002 \\
\hline & \#cohort fixed effects & $(0.0029)$ & $(0.0015)$ & $(0.0015)$ \\
\hline & & $*$ & $* *$ & \\
\hline & ymean & 0.08 & 0.67 & 0.75 \\
\hline & $\mathrm{N}$ obs & 279954 & 310427 & 293641 \\
\hline & $\mathrm{N}$ muncipalities & 430 & 430 & 430 \\
\hline
\end{tabular}

Note: Each new model encompasses all of the preceding. "Aggregate fixed effects" includes municipality fixed effects and county-year fixed effects. "Municipality covariates" includes average years of schooling attained, male and female income levels, male and female employment rates, all measured in the year of birth. "Parental covariates" includes education level fixed effects and income for both parents, all measured in the year of birth. "Pre-reform population density" is the share of the municipality inhabitants living in a "densely populated" area in 1980. "Pre-reform municipality covariates" includes 1980 levels of the municipality covariates. "Pre-reform ability" denotes average ability score of men residing in the municipality in 1980. When adding municipality baseline characteristics-cohort interactions from row (1) to (2), the joint $\chi^{2}$ values for the 65 added terms range from 128 to 170. Standard errors clustered on municipality. Standard errors in parentheses. ${ }^{*} \mathrm{p}<0.10,{ }^{* *} \mathrm{p}<0.05, * * *$ $\mathrm{p}<0.01$.

We build our discussion of the results on the estimates reported in row (3), which includes the most extensive controls for differential trends related to pre-reform local characteristics. That model is also the one we use as the basis for extensions in sections 5.1 and 6.1.

With the standardized cognitive ability score as the outcome, this specification gives an estimated coefficient on our television exposure measure of -0.0053 , i.e. a negative effect of 
exposure of $0.53 \%$ of a standard deviation. Since the IQ scale has a standard deviation of 15 , this estimated effect of one additional year of full television coverage would roughly correspond to a 0.08 points reduction in IQ. By comparison, Brinch and Galloway (2012) estimate the effect of one year of schooling to be around 3.7 IQ points using an education reform in Norway in the 1960s. Likewise, Carlsson, Dahl, Öckert, and Rooth (2015) use a quasi-experimental setting in Sweden to exploit variation in test taking date for young Swedish males preparing for military service. Their results imply that one year of schooling raises crystallized (synonyms and technical comprehension) test scores by around $20 \%$ of a standard deviation, corresponding to around 3 IQ points, but has no effect on fluid (spatial and logic) intelligence tests. Taken at face value, our estimate thus indicates that 18 years of full cable TV coverage has a negative impact on cognitive ability (-1.5 IQ) comparable to around half a year's schooling. Further analysis show that the effects are concentrated at the middle and lower upper part of the ability distribution.

Moving on to high-school completion, our results indicate that one extra year of cable TV coverage reduces the probability of high-school completion for men by age 21 by around 0.3 percentage points. To again put the results in perspective, we note that the estimated effect on high-school completion of one year of cable TV exposure constitute 1/15 of the corresponding statistical association between one additional year of parental education and high school completion, as reported by Bratsberg, Raaum, and Røed (2012, Figure 5). For women, we find no effect at all on high-school completion, regardless of model specification. This shows that we are not simply picking up some general, local trends, and is consistent with the research showing greater importance of the home and school inputs for boys than for girls. Boys' higher impatience may also make them more susceptible to the temptation of easy entertainment at the expense of more cognitively challenging activities. 


\section{Alternative models and additional robustness checks}

In this section, we first assess our findings robustness with respect to the source of identification. This is done by setting up a model with identification based on within-family variation in television exposure only (Section 5.1), and by exclusively using data from the largest municipalities (Section 5.2). Second, we take a closer look at the possibility of parental selection at baseline by using parental characteristics as outcomes in a "placebo" analysis (Section 5.3).

\subsection{Family fixed effects}

A particularly reliable source of identification of cable TV effects would be to compare brothers or sisters who have been subjected to different exposure intensities due to differences in age. Identification with family fixed effects will in practice only come from younger brothers or sisters having higher television exposure, thus we include fixed effects for sibling order in addition to family fixed effects to be sure not to pick up birth order effects. In addition, we include the full vector of controls from Equation (1), insofar as they are not absorbed by the family fixed effects. When running this demanding specification, the point estimates are no longer statistically significant; conf. Table V. It is reassuring, though, that the point estimates are almost identical to those from the baseline specification. 


\section{Table $V$}

Instrumental Variables Estimates of the Effects of One Additional Year With Cable Television Coverage. With Family Fixed Effects.

\begin{tabular}{|c|c|c|c|}
\hline & \multicolumn{2}{|c|}{ Men } & Women \\
\hline & Ability & $\begin{array}{l}\text { High School } \\
\text { graduate }\end{array}$ & $\begin{array}{l}\text { High School } \\
\text { graduate }\end{array}$ \\
\hline TV & $\begin{array}{l}-0.0053 \\
(0.0140)\end{array}$ & $\begin{array}{l}-0.0030 \\
(0.0075)\end{array}$ & $\begin{array}{c}-0.0004 \\
(0.0104)\end{array}$ \\
\hline $\begin{array}{l}\text { ymean } \\
\mathrm{N} \text { obs } \\
\mathrm{N} \text { families with }>1 \text { sibling }\end{array}$ & $\begin{array}{c}0.08 \\
279954 \\
54101\end{array}$ & $\begin{array}{c}0.67 \\
310427 \\
60755\end{array}$ & $\begin{array}{c}0.75 \\
293641 \\
54201\end{array}$ \\
\hline
\end{tabular}

Note: All models are based on Equation (1), and include family fixed effects, (same-sex) sibling order fixed effects, municipality fixed effects, county-year fixed effects, municipality covariates (average years of schooling attained, male and female income levels, male and female employment rates), and interactions between cohort fixed effects and the 1980 levels of population density, the municipality covariates, and average ability score of men residing in the municipality. Standard errors clustered on municipality. Standard errors in parentheses. * $\mathrm{p}<0.10, * * \mathrm{p}<0.05, * * * \mathrm{p}<0.01$.

\subsection{Identification based on data from the largest municipalities only}

As pointed out in Section 3, the use of county-year fixed effects in our main empirical analysis implies that we have not (so far) exploited data from Oslo, the capital. This is unfortunate, as Oslo has been in the forefront of the cable TV expansion development. As an alternative approach, we now focus exclusively on the most heavily populated areas in Norway, which were in the forefront of the cable television rollout; i.e. we construct two samples; one consisting of municipalities with a population in 1980 of above 20,000 (21 municipalities) and one with municipalities exceeding 30,000 inhabitants (10 municipalities). Using these samples addresses two concerns: One is that there may have been unobserved factors impacting cognitive skills and educational and labor market outcomes of young people in large cities and other urban areas in this period, and that this is picked up by our television measure, since the expansion largely took place in populous areas. Another concern is that the expansion to some 
extent was demand-driven after all, and that the demand for cable TV could be correlated with the trends in our outcome measures. Though we cannot completely rule out that this is a possibility for very small municipalities, such a mechanism would be an unlikely factor to drive the results in a comparison between large municipalities.

Given that we only use a small number of municipalities with similar population density and demographic composition in these exercises, we substitute common year fixed effects for both the county-by-year fixed effects and for the pre-reform municipality characteristics interacted with cohort dummies. This implies the foundation for identification becomes very different from the one used in the baseline model. The results are shown in Table VI. Standard errors blow up with the reduced sample size, but the estimated effects remain similar - though far from identical - to those from the baseline model.

\section{Table VI}

Instrumental Variables Estimates of the Effects of One Additional Year With Cable Television Coverage. Data From the Largest Municipalities Only

\begin{tabular}{lcc|c}
\hline \hline & \multicolumn{2}{c|}{ Men } & Women \\
\hline \hline & Ability & $\begin{array}{c}\text { High School } \\
\text { graduate }\end{array}$ & $\begin{array}{c}\text { High School } \\
\text { graduate }\end{array}$ \\
\hline \hline $\begin{array}{l}\text { 10 largest municipalities } \\
\text { population in }\end{array}$ & -0.0091 & -0.0075 & 0.0037 \\
1980 $>30,000)$ & $(0.0068)$ & $(0.0035)$ & $(0.0033)$ \\
ymean & & 0.69 & 0.76 \\
N obs & 5.41 & 87072 & 81800 \\
N muncipalities & 78957 & 10 & 10 \\
\hline \hline 21 largest municipalities & 10 & -0.0063 & 0.0024 \\
(population in & -0.0039 & $(0.0020)$ & $(0.0019)$ \\
1980>20,000) & $(0.0038)$ & $* *$ & \\
ymean & & 0.68 & 0.75 \\
N obs & 5.35 & 116028 & 109430 \\
N muncipalities & 104984 & 21 & 21 \\
\hline \hline
\end{tabular}

Note: All models include municipality fixed effects, year fixed effects, municipality covariates (average years of schooling attained, male and female income levels, male and female employment rates) and individual-level covariates (education level fixed effects and income for both parents). Robust standard errors. Standard errors in parentheses. ${ }^{*} \mathrm{p}<0.10,{ }^{* *} \mathrm{p}<0.05$, $* * * \mathrm{p}<0.01$. 


\subsection{Parental selection into treatment}

Even though we measure television exposure at the baseline (municipality of birth), we may be concerned that would-be parents have already selected into certain municipalities before having children. If this generated an increasingly negatively selected population in TV-intensive municipalities, this could distort our estimates. To investigate this, we perform placebo regressions using as dependent variables the (pre-determined) parental covariates we use as control in our baseline specification. Apart from the absence of the parental covariates, the models estimated here correspond to those in the table of our main results, Table IV. The results are shown in Table VII. The estimated coefficients are small and do not show any clear pattern.

\section{Table VII}

Placebo regressions - OLS Estimates of the Effects On Parental Characteristics of One Additional Year With (Future) Cable Television Coverage In the Child's Birth Municipality

\begin{tabular}{lccc|ccc}
\hline \hline & \multicolumn{3}{c|}{ Father } & \multicolumn{3}{c}{ Mother } \\
\hline \hline$(1)$ & $\begin{array}{c}\text { High School } \\
\text { degree }\end{array}$ & $\begin{array}{c}\text { University } \\
\text { degree }\end{array}$ & Income & $\begin{array}{c}\text { High School } \\
\text { degree }\end{array}$ & $\begin{array}{c}\text { University } \\
\text { degree }\end{array}$ & Income \\
& -0.001 & 0.001 & -0.123 & -0.001 & 0.000 & -0.043 \\
& $(0.001)$ & $(0.001)$ & $(0.108)$ & $(0.001)$ & $(0.001)$ & $(0.073)$ \\
\hline$(2)$ & -0.001 & 0.002 & 0.032 & -0.001 & 0.001 & -0.089 \\
& $(0.001)$ & $(0.001)$ & $(0.087)$ & $(0.001)$ & $(0.001)$ & $(0.074)$ \\
\hline$(3)$ & -0.001 & 0.002 & -0.032 & -0.001 & 0.001 & -0.089 \\
& $(0.001)$ & $(0.001)$ & $(0.087)$ & $(0.001)$ & $(0.001)$ & $(0.074)$ \\
\hline ymean & 0.70 & 0.19 & 66.02 & 0.64 & 0.16 & 23.70 \\
N obs & 378414 & 378414 & 378414 & 378265 & 378265 & 378265 \\
N muncipalities & 430 & 430 & 430 & 430 & 430 & 430 \\
\hline \hline
\end{tabular}

Note: Parents of both boys and girls. Parents are included the first time they appear as a parent in the sample. (1) includes municipality fixed effects, county-year fixed effects, "Municipality covariates" (average years of schooling attained, male and female income levels, male and female employment rates, all measured in the year of birth), and the share of the municipality inhabitants living in a "densely populated" area in 1980 interacted with cohort fixed effects. (2) includes also 1980 levels of the municipality covariates interacted with cohort fixed effects. (3) includes also average ability score of men residing in the municipality in 1980 interacted with cohort fixed effects. Standard errors clustered on municipality. Standard errors in parentheses. $* \mathrm{p}<0.10, * * \mathrm{p}<0.05, * * * \mathrm{p}<0.01$. 


\section{Mechanism}

Since we do not have geographically disaggregated data on television watching, we can only estimate the intention-to-treat effect of television coverage; however we can shed some light on the likely mechanism by analyzing heterogeneous effects across different ages of exposure and also by looking at auxiliary data sources regarding youths' actual time use.

\subsection{Exposure at different ages}

In our baseline model, we have assumed that commercial television exposure has the same impacts on cognitive ability and schooling outcomes, regardless of its timing within the 0-18 year age span. This is a questionable assumption. The literature on the importance of relatively early environments (Heckman, 2006; Chetty, Hendren, and Katz, 2015; Conti, Heckman, and Pinto, 2015) and "critical periods" for cognitive development (Bleakley and Chin, 2004; van den Berg, Lundborg, Nystedt, and Rooth, 2014) suggests strongest effects in the pre-school and elementary school periods. On the other hand, the fact that actual television watching in general increases with age may pull in the other direction (see Figure 5 in the next subsection).

To shed some light on this issue, we have split the television exposure variable into three separate periods of six years each, corresponding to the pre-school, elementary school, and middle and high school periods, and studied the impacts of television exposure of these three periods in separate models. As we can see from Table VIII, the prediction that the relatively early periods are particularly important is confirmed in this analysis. The impacts on cognitive ability are largest for exposure during pre-school and elementary school age, whereas the impacts on high school completion are largest for exposure during elementary school age. While the results in Table VIII stems from separate regression models, we have also estimated instrumental variables models where we enter all the age-specific exposure variables simultaneously. It turns out to be difficult to identify such a model in practice, however, since 
the three endogenous variables and their respective instruments are so highly correlated, and since there is an unfortunate deterministic relationship between the three instruments (for the municipalities of birth, it is not possible to increase exposure in an early period without at the same time increase it in later periods). That being said, the point estimates coming out of such an analysis are not very different from those shown in Table VIII, and the conclusion that the two earliest periods are most important remains the same.

\section{Table VIII}

Instrumental Variables Estimates of the Effects of One Additional Year With Cable Television Coverage. Separate Regression Models By Age of TV Exposure

\begin{tabular}{lcc|c}
\hline \hline & \multicolumn{2}{c|}{ Men } & Women \\
\hline \hline TV 0-5 & Ability & $\begin{array}{c}\text { High School } \\
\text { graduate }\end{array}$ & $\begin{array}{c}\text { High School } \\
\text { graduate }\end{array}$ \\
& -0.0073 & -0.0039 & 0.0010 \\
TV 6-12 & $(0.0042)$ & $(0.0019)$ & $(0.0020)$ \\
& -0.0078 & -0.0063 & -0.0025 \\
TV 13-18 & $(0.0063)$ & $(0.0035)$ & $(0.0032)$ \\
& -0.0031 & -0.0003 & -0.0001 \\
ymean & $(0.0078)$ & $(0.0043)$ & $(0.0048)$ \\
N obs & 0.08 & 0.67 & 0.75 \\
N muncipalities & 279954 & 310427 & 293641 \\
\hline \hline
\end{tabular}

Note: All models are based on Equation (1), and include municipality fixed effects, county-year fixed effects, municipality covariates (average years of schooling, male and female income levels, male and female employment rates), individual-level covariates (education level fixed effects and income for both parents), and interactions between cohort fixed effects and the 1980 levels of population density, the municipality covariates, and average ability score of men residing in the municipality. Standard errors clustered on municipality. Standard errors in parentheses. ${ }^{*} \mathrm{p}<0.10, * * \mathrm{p}<0.05, * * * \mathrm{p}<0.01$.

\subsection{Television consumption}

Access to commercial television channels can affect the nature of television consumption in two ways: By affecting the total time spent watching TV and by affecting the type of programs 
being watched. In this subsection, we use auxiliary data from media surveys to shed light on these possible mechanisms. Statistics Norway has since 1991 undertaken surveys of the population's media habits. When it comes to television, respondents are asked both about what type of connection they have, and about how much they watched yesterday. An effort is made to obtain responses from kids as young as 9 years old, thus for the age group 9-18 we can get a quite good picture of how having a cable connection correlates with actual television watching in the period from 1991 onwards. Error! Reference source not found.VI shows age profiles for actual television watching "yesterday" for those with and without a cable television connection. Up to age 14, there is a steady increase in the number of minutes spent on television watching for both groups. And those with cable connection watch considerably more television than those without. The two age profiles have a very similar shape, however, suggesting that the heterogeneous effects by age estimated above are not simply due to differences in the amounts of television consumption.

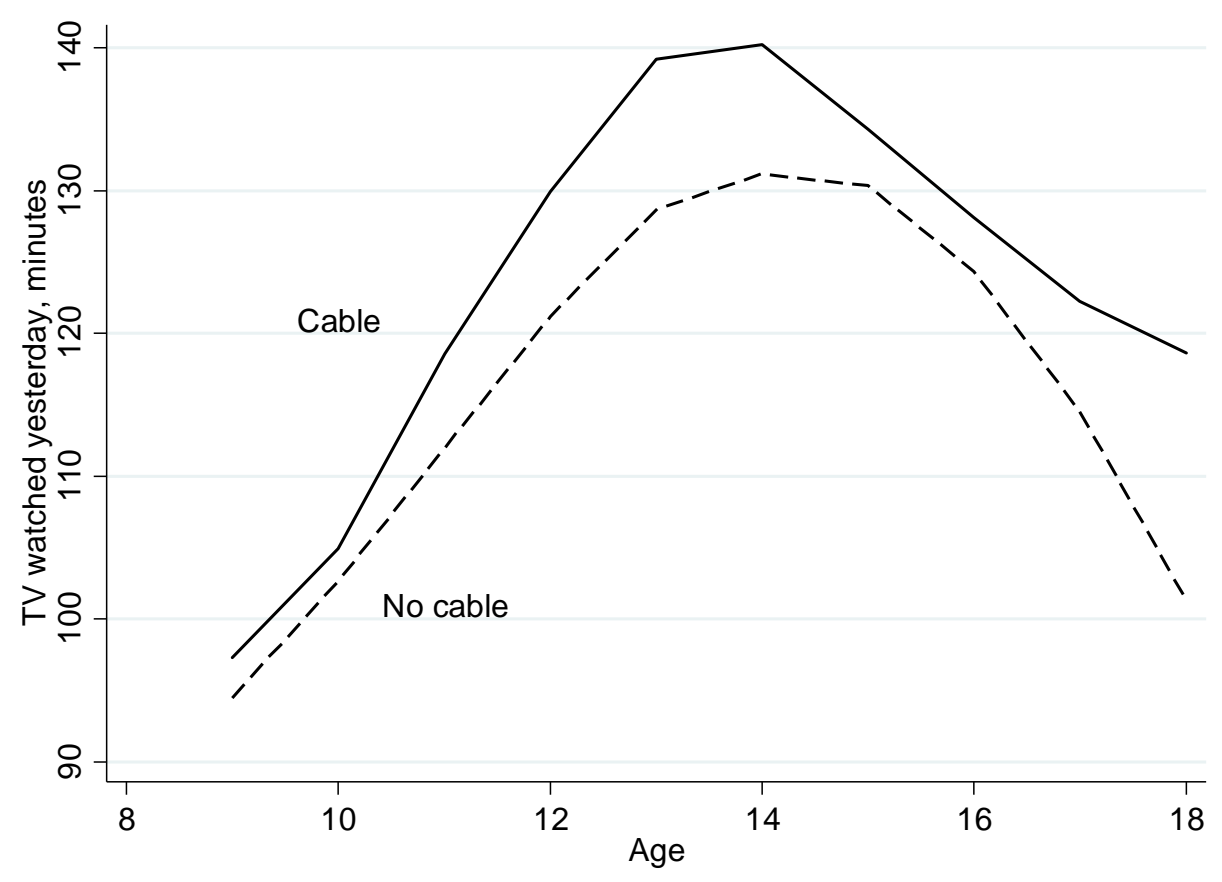

Figure VI

Television Watching by Age (Smoothed), From the Media Use Survey 1991-2004 
The Norwegian Broadcasting Corporation (NRK), which held a legal monopoly until 1981, has had and continues to have a broad public service mandate. In their articles of association, it is stated that "The purpose of the NRK's overall public media services is to meet democratic, social and cultural needs in society (NRK, 1997)." Further, "[t]he NRK should promote public debate," "offer services which can be a source of inspiration, reflection, experience and knowledge through programs of high quality," and "contribute to public education and learning." The new channels that arrived with cable television had no public service mandate, and no regulation of content other than pornography and violence (Regulations relating to broadcasting, 1997). And their program profiles were indeed markedly different: According to a comparative analysis undertaken in 1993, the content of the main Scandinavian cable channels in Norway (TVNorge and TV3) were $75 \%$ entertainment and $10 \%$ advertisements, while that of the NRK was almost $40 \%$ news, documentaries, science, nature, or similar (NRK, 1993) and no advertisements. It is also clear that the new channels were watched - in 1992, the NRK's share of total viewing time was down to $64 \%$ (MMI, 1992).

In the media survey, respondents are also asked what type of programs they watched yesterday, and each program is coded as belonging to one of several categories. To examine the relationship between cable television access and the type of programs being watched, we aggregate these categories into two groups: "Educational" (news, debates, information and documentaries, science, nature, quiz) and "Other" (sports, kids/youth, religious, theatre and ballet, classical music, films, TV series, pop music, other entertainment, other). Thus we have measures of how many shows of these types each individual watched yesterday. We also investigate total time spent watching television and spent reading yesterday. To come as close as possible to the approach in our main analysis, we include fixed effects for area type (population>100 000, $20000-100000,<20000$, "rural") and year. 
The results are presented in Table IX. They indicate that for both boys and girls, access to cable television implies much more television watching, as well as a marked shift toward non-educational shows. There is one interesting difference in the male and female responses; however, namely that television watching appears to substitute for reading activities for boys, but not for girls. The fact that the impact of cable television access on the overall television consumption pattern is quite similar for boys and girls suggests that the heterogeneous impact on high school graduation that we estimated earlier is either due to television watching crowding out reading to a greater extent for boys than for girls, or that boys are more sensitive to changes in television exposure. 
Table IX

Cable Connection and Television Consumption of Adolescents Aged 9-18

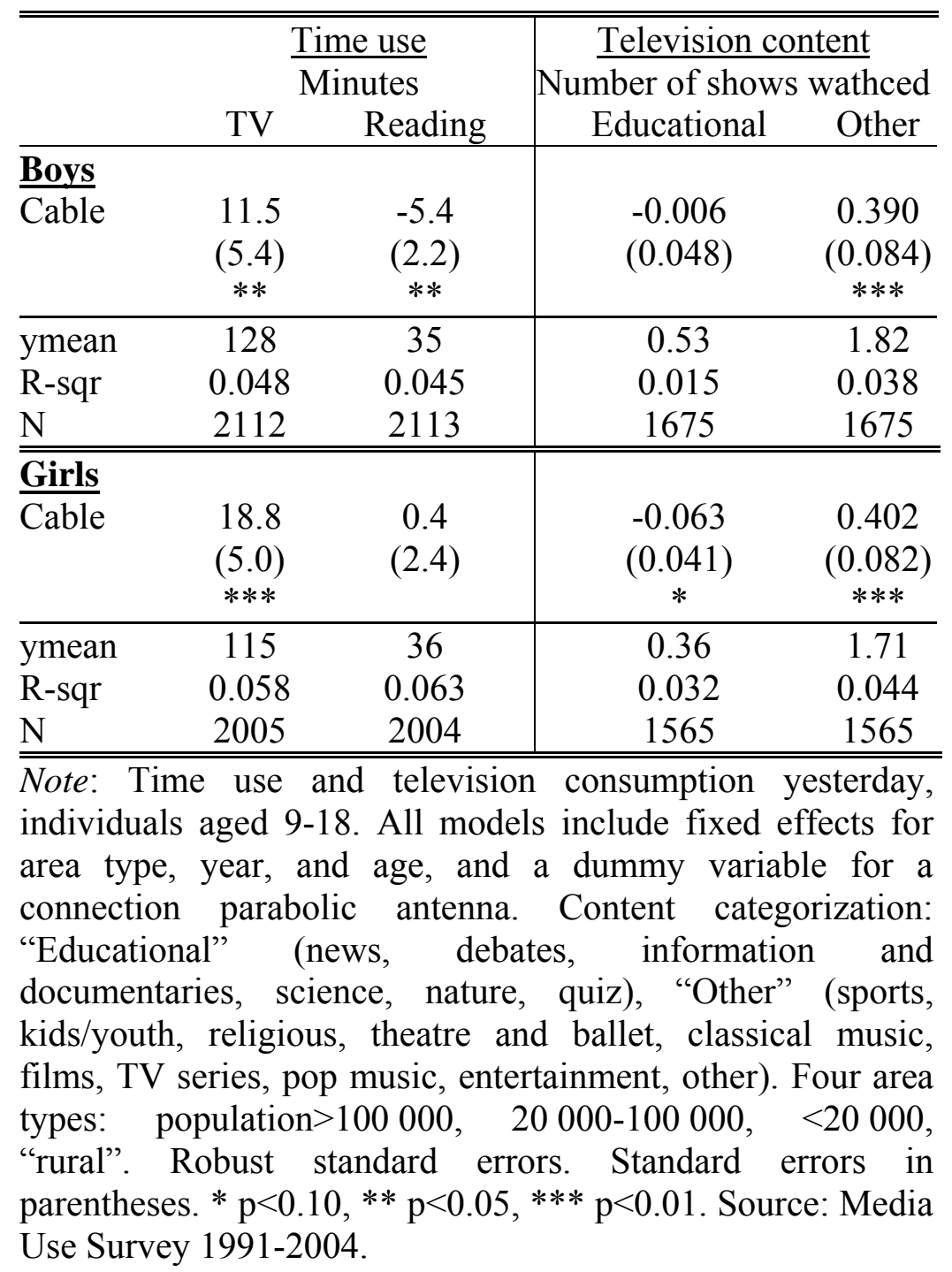

\section{Conclusion}

In this paper, we have used the geographically staggered expansion of cable TV in Norway during the 1980s and 1990s to examine the impacts of access to commercial TV channels on children and youths. Our outcome measures include ability test scores (measured at age 18) for men and high school completion at age 21 for both men and women. Our findings indicate that commercial TV affects ability test scores and high school completion rates negatively for men, but has no effect on high school completion for women. The estimated effects on male outcomes are moderately sized, but far from negligible. For example, one year of full cable 
television coverage lowers intelligence test scores by more than $0.5 \%$ of a standard deviation, corresponding to 0.08 IQ points. This is roughly $2 \%$ of the previously estimated impact of one year extra schooling (Brinch and Galloway, 2012). The same increase in cable TV reduces the high-school completion rate of men at age 21 by around 0.3 of a percentage point. Even though these point estimates appear small, it should be kept in mind that they accumulate each exposed year.

We started out this paper by pointing out that many countries have seen a recent decline in intelligence test scores and questioned whether this could be explained by the increased access to commercial television channels. During the data period covered by our analysis, the average IQ score among Norwegian male conscripts declined by around 1.9 points (conf. Figure IV), and average cable television exposure increased by three years. Based on our baseline model and data for aggregate cable televsion coverage, we estimate that the expansion of cable TV can account for a 0.24 point decline; i.e. around $12 \%$ of the overall decline. Hence, although we do find negative effects of commercial televion access on cognitive ability, the rollout of cable television can only explain a modest fraction of the apparent overall decline in IQ scores.

Another motivation was the educational gender gap. In the same manner as with intelligence test scores, we can calculate cable television's contribution to the increasing gender gap in high school graduation. Taking the estimates of a zero effect for women and a negative effect of 0.33 percentage points per year of exposure for men, we get that cable television explains 1 percentage point decline in high school gradution for men in this period, or about $1 / 6$ of the increase in the gender gap. One may speculate whether the asymmetric effect across gender, which has a priori support in previous research, applies also to other types of media that provide light entertainment. 
The negative impacts are largest for TV exposure before the age of 12 years. It is probable that the developmental impacts of increased supply of TV entertainment during childhood depend both on the extent to which the actual consumption of entertainment is regulated by parents and on the kind of activities TV consumption substitutes for. Data from time-use and media surveys indicate that the increase in TV consumption to a large extent substituted for reading, particularly for boys; hence, one may hypothesize that the negative effects identified in our paper do not stem from increases in TV consumption per se, but rather by the resultant reduction in reading activities.

\section{References}

American Academy of Pediatrics (2001). Children, Adolescents, and Television, Committee on Public Education, Pediatrics 2001; 107(2): 423-426.

Bertrand, Marianne and Jessica Pan (2013). The Trouble with Boys: Social Influences and the Gender Gap in Disruptive Behavior. American Economic Journal: Applied Economics, 5(1): 32-64.

Bettinger, Eric, and Slonim, Robert (2007). Patience among Children. Journal of Public Economics, 91(1): 343-363.

Bleakley, Hoyt and Aimee Chin (2004). Language Skills and Earnings: Evidence from Childhood Immigrants. Review of Economics and Statistics, 86(2): 481-496.

Bratsberg, Bernt, Oddbjørn Raaum, and Knut Røed (2012). Educating Children of Immigrants: Closing the Gap in Norwegian Schools. Nordic Economic Policy Review, 3(1):211-252.

Brinch, Christian N. and Galloway, Taryn Ann (2012). Schooling In Adolescence Raises IQ Scores. Proceedings of the National Academy of Sciences, 109(2):425-430.

Campbell, Frances, Gabriella Conti, James J. Heckman, Seong Hyeok Moon, Rodrigo Pinto, Elizabeth Pungello, and Yi Pan (2014). Early Childhood Investments Substantially Boost Adult Health. Science, 343 (6178), 1478-1485.

Card, David (1999). The Causal Effect of Education on Earnings. In the Handbook of Labor Economics, Vol. 3A, O. Ashenfelter and D. Card, Eds. Amsterdam: Elsevier Science 
Carlsson, Magnus, Gordon B. Dahl, Björn Öckert, and Dan-Olof Rooth (2015). The Effect of Schooling on Cognitive Skills. Review of Economics and Statistics, 97(3): 533-547.

Castillo, Marco, Paul J. Ferraro, Jeffrey L. Jordan, and Ragan Petrie (2011). The Today and Tomorrow of Kids: Time Preferences and Educational Outcomes of Children. Journal of Public Economics 95(11): 1377-1385.

Chetty, Raj, John N. Friedman, Nathaniel Hilger, Emmanual Saez, Diane Whitmore Schanzenbach, and Danny Yagan. (2011). How Does Your Kindergarten Classroom Affect Your Earnings? Evidence from Project Star. The Quarterly Journal of Economics, 126 (4): 1593-1660.

Chetty, Raj, Nathaniel Hendren, and Lawrence F. Katz (2015). The Effects of Exposure to Better Neighborhoods on Children: New Evidence from the Moving to Opportunity Experiment. NBER Working Paper No. 21156.

Cho, Donghun (2007). The role of high school performance in explaining women's rising college enrollment, Economics of Education Review, 26(4): 450-462.

Chong, Alberto, and Eliana La Ferrara (2009). Television and Divorce: Evidence from Brazilian Novelas. Journal of the European Economic Association, 7(2-3):458-468.

Conti, Gabriella, James Heckman, and Rodrigo Pinto (2015). The Effects of Two Influential Early Childhood Interventions on Health and Healthy Behaviors, NBER Working Paper No. 21454.

Cotton, Sue M., Patricia Kiely, David P. Crewther, Brenda Thompson, Robin Laycock, and Sheila G. Crewther (2005). A Normative and Reliability Study of the Raven's Coloured Matrices for Primary School Aged Children from Victoria, Australia. Personality and Individual Differences, 39:647-659.

Cunha, Flavio and James Heckman (2007). The Technology of Skill Formation. American Economic Review, 97(2):31- 47.

DellaVigna, Stefano and Ehan Kaplan (2007). The Fox News Effect: Media Bias and Voting. The Quarterly Journal of Economics, 122(3):1187-1234.

Dohmen, Thomas, Armin Falk, David Huffman, and Uwe Sunde (2010). Are Risk Aversion and Impatience Related to Cognitive Ability? American Economic Review, 100(3):1238-60. 
Dutton, Edward and Richard Lynn (2013). A Negative Flynn Effect in Finland, 1997-2009. Intelligence, 41:817-820.

Dutton, Edward and Richard Lynn (2015) A Negative Flynn Effect in France, 1999 to 2008-9. Intelligence, 51:67-70.

Enikolopov, Ruben, Maria Petrova, and Ekaterina Zhuravskaya, E. (2011). Media and Political Persuasion: Evidence from Russia. The American Economic Review, 101(7):3253-3285.

Fortin, Nicole, Philip Oreopoulos, and Shelley Phipps (2015). Leaving Boys Behind. Gender Differences in High Academic Achievement. The Journal of Human Resources, 50(3):449-479.

Gentzkow, Matthew (2006). Television and Voter Turnout. The Quarterly Journal of Economics, 121(3):931-972.

Gentzkow, Matthew, and Jesse M. Shapiro (2008). Preschool Television Viewing and Adolescent Test Scores: Historical Evidence from the Coleman Study. The Quarterly Journal of Economics, 123(1):279-323.

Goldin, Claudia, and Lawrence F. Katz (2008). The Race between Education and Technology. Cambridge and London: Harvard University Press, Belknap Press.

Goldin, Claudia, Lawrence F. Katz, and Ilyana Kuziemko (2006). The Homecoming of American College Women: The Reversal of the College Gender Gap, Journal of Economic Perspectives, 20(4): 133-156, Fall.

Golsteyn, Bart H., Hans Grönqvist, and Lena Lindahl (2014). Adolescent Time Preferences Predict Lifetime Outcomes. The Economic Journal 124(580): F739-F761.

Griliches, Zvi, and William M. Mason (1972). Education, Income, and Ability. Journal of Political Economy, 80:S74-S103.

Hanushek, Eric A., and Ludger Woessmann, L. (2008). The Role of Cognitive Skills in Economic Development. Journal of Economic Literature, 46(3):607-668.

Havnes, Tarjei, and Magne Mogstad (2011). No Child Left Behind: Subsidized Child Care and Children's Long-run Outcomes, American Economic Journal: Economic Policy 3: 97-129.

Heckman, James (2006). Skill Formation and the Economics of Investing in Disadvantaged Children. Science, 312(5782):1900-1902. 
Jensen, Robert and Emily Oster (2009). The Power of TV: Cable Television and Women's Status in India. The Quarterly Journal of Economics, 124(3):1057-1094.

Jolin, Edith M., and Ronald A. Weller (2011). Television Viewing and Its Impact on Childhood Behaviors. Current Psychiatry Reports, 13:122-128.

Johnson, Steven (2006). Everything Bad Is Good For You. Penguin.

Kearney, Melissa, and Philip B. Levine (2015). Early Childhood Education by MOOC: Lessons from Sesame Street. NBER Working Paper 21229.

Kristensen, Petter, and Tor Bjerkedal (2007). Explaining the Relation between Birth Order and Intelligence. Science, 316(5832):1717-1717.

Krueger, Alan (1999). Experimental Estimates of Production Functions The Quarterly Journal of Economics, 114(2):497-532.

La Ferrara, Eliana, Alberto Chong, and Suzanne Duryea (2012). Soap Operas and Fertility: Evidence from Brazil. American Economic Journal: Applied Economics, 4(4):1-31.

Martin, Gregory J., and Ali Yurukoglu (2014). Bias in Cable News: Real Effects and Polarization. NBER Working Paper 20798.

Machin, Stephen, and Sandra McNally (2008). The Literacy Hour. Journal of Public Economics, 92(5-6):1441-1462.

MMI (1992). Television Viewing Survey. Data provided by Medienorge, TV-kanalenes seertall per år - resultat. http://medienorge.uib.no/statistikk/medium/tv/219. [Online; accessed 2015-05-10].

Norwegian Ministry of Culture (1995). NOU 1995:8. Broadcasting In Cable Networks. Technical Report, Norwegian Ministry of Culture White Paper.

Norwegian Ministry of Culture (1999). Stortingsmelding 46-1998-1999 Digitalt Fjernsyn.

NRK (1993) Program Profile for Norwegian TV-Channels. NRK, Department of Analysis. Data provided by Medienorge, Program profile for Norwegian TV-channels. http://medienorge.uib.no/statistikk/medium/tv/136. [Online; accessed 2015-05-10].

NRK AS (1996). Articles of Association. [Vedtekter for Norsk rikskringkasting AS.]

Olken, Ben A. (2009). Do Television and Radio Destroy Social Capital? Evidence from Indonesian Villages. American Economic Journal: Applied Economics, Pages 1-33. 
Organisation for Economic Co-operation and Development (2014). Education at a Glance 2014: OECD Indicators. Paris and Washington, D.C.: Organisation for Economic Co-operation and Development.

Postman, Neil (1985). Amusing Ourselves To Death: Public Discourse In the Age of Television. New York: Penguin Books.

Regulations Relating to Broadcasting (1997). Regulations relating to broadcasting and audiovisual on-demand services. [Forskrift om kringkasting og audiovisuelle bestillingstjenester.]

Rönnlund, Michael, Berit Carlstedt, Yulia Blomstedt, Lars-Göran Nilsson, and Lars Weinehall (2013). Secular Trends in Cognitive Test Performance: Swedish Conscript Data 1970-1993. Intelligence, 41:19-24.

Riphahn, IRegina T., and Caroline Schwientek (2015) What drives the reversal of the gender education gap? Evidence from Germany, Applied Economics, 47(53):5748-5775.

Shayer, Michael, Denise Ginsburg, and Robert Coe (2007). Thirty Years On - A Large Anti-Flynn Effect? The Piagetian Test Volume and Heaviness Norms 1975-2003. Journal of Educational Psychology, 77:25-41.

Strasburger, Victor C., Amy B. Jordan, and Ed Donnerstein (2010). Health Effects of Media On Children and Adolescents. Pediatrics, $125(4)$ ):756-767.

Sundet, Jon Martin, Dag G. Barlaug, and Tore M. Torjussen (2004). The End of the Flynn Effect? A Study of Secular Trends In Mean Intelligence Test Scores of Norwegian Conscripts During Half A Century. Intelligence, 32(4):349-362.

Teasdale, Thomas W., and David R. Owen (2008) Secular Declines in Cognitive Test Scores: A Reversal of the Flynn Effect. Intelligence, 36:121-126.

Thakkar, Rupin R., Michelle M. Garrison, and Dimitri A. Christakis (2006). A Systematic Review for the Effects of Television Viewing By Infants and Preschoolers. Pediatrics, 118(5):2025-2031. van den Berg, Gerard J., Petter Lundborg, Paul Nystedt, Dan-Olof Rooth (2014). Critical Periods during Childhood and Adolescence. Journal of the European Economic Association, 12(6):15211557. 
Woodley, Michael Anthony, and Gerhard Meisenberg (2013). In the Netherlands the Anti-Flynn Effect is a Jensen Effect. Personality and Individual Differences, 54:871-876. 